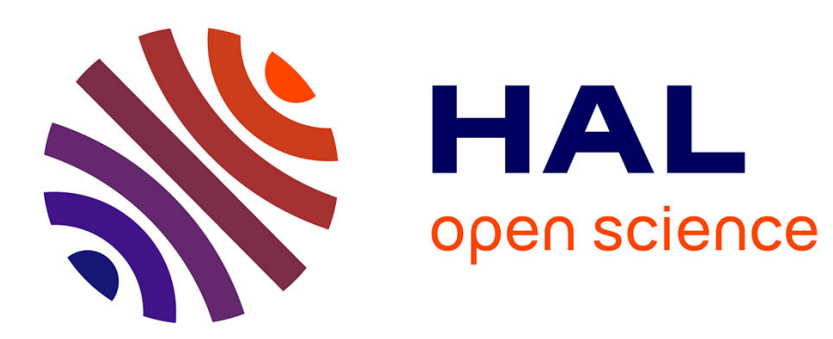

\title{
Aluminum metallization and wire bonding aging in power MOSFET modules
}

Roberta Ruffilli, M Berkani, P Dupuy, S Lefebvre, Y Weber, Bénédicte Warot-Fonrose, Cécile Marcelot, Marc Legros

\section{- To cite this version:}

Roberta Ruffilli, M Berkani, P Dupuy, S Lefebvre, Y Weber, et al.. Aluminum metallization and wire bonding aging in power MOSFET modules. 2017. hal-01491384

\section{HAL Id: hal-01491384 \\ https://hal.science/hal-01491384}

Preprint submitted on 17 Mar 2017

HAL is a multi-disciplinary open access archive for the deposit and dissemination of scientific research documents, whether they are published or not. The documents may come from teaching and research institutions in France or abroad, or from public or private research centers.
L'archive ouverte pluridisciplinaire HAL, est destinée au dépôt et à la diffusion de documents scientifiques de niveau recherche, publiés ou non, émanant des établissements d'enseignement et de recherche français ou étrangers, des laboratoires publics ou privés. 


\section{ScienceDirect}

Materials Today: Proceedings XX (2017) XXX-XXX materialstoday: PROCEEDINGS

www.materialstoday.com/proceedings

EDS 2016

\title{
Aluminum metallization and wire bonding aging in power MOSFET modules
}

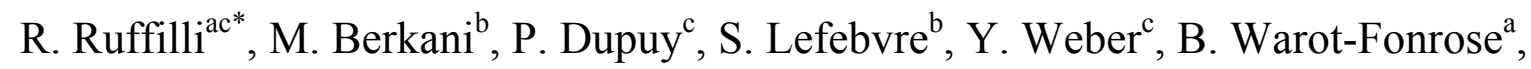 \\ C. Marcelot ${ }^{\mathrm{a}}, \mathrm{M}$. Legros $^{\mathrm{a}}$ \\ ${ }^{a}$ CEMES-CNRS, 29 rue J. Marvig, Université de Toulouse, 31055 Toulouse, France \\ ${ }^{b}$ Laboratoire SATIE, ENS-Cachan, 61 Avenue du Président Wilson, 94235 Cachan, France \\ ${ }^{c}$ NXP Semiconductors France SAS, 134 Avenue du Général Eisenhower, 31100 Toulouse, France
}

\begin{abstract}
A limiting factor for the long-term reliability of power MOSFET-based devices is the electro-thermal and/or thermo-mechanical aging of the metallic parts. In this paper we assess the bonding wire and source metallization degradation of power devices, designed for applications in the automotive industry. Our approach consists in characterizing the metal microstructure before and after accelerated aging tests, by scanning electron microscopy, ion milling and microscopy, focused ion beam tomography, transmission electron microscopy and grain structure mapping. To focus on the wire-metallization bonding interface, we have set up a dedicated sample preparation that allows us to disclose the metallization under the bonding wires. This critical location is significantly different from the naked metallization, as the bonding process induces plastic deformation prior to aging. The main mechanism behind the device failure is the generation and propagation of fatigue cracks in the aluminum metallization. Away and under the wire bonds, they run perpendicularly from the surface down to the silicon substrate following the grain boundaries, due to an enhanced self-diffusion of aluminum atoms. Moreover, initial imperfections in the wire-metallization bonding (small cavities and aluminum oxide residues) are the starting point for harmful cracks that propagate along the wire-metallization interface and can eventually cause the wire lift-off. These phenomena can explain the local increase in the device resistance occurring at failure.
\end{abstract}

Keywords: Power MOSFET-based device; Metallization microstructure aging; Scanning electron microscopy (SEM); Ion milling; Ion microscopy; Focused ion beam (FIB) tomography; Transmission electron microscopy (TEM); Grain structure mapping

\footnotetext{
* Corresponding author. Tel.: +33-(0)5-62-25-7818; fax: +33-(0)5-62-25-7999.

E-mail address: roberta.ruffilli@cemes.fr
} 


\section{Introduction}

The development of hybrid, mild hybrid and electric cars along with the integration of smart technologies have boosted the power electronics in automotive applications. Modern power MOSFET devices integrate several advanced capabilities in the field of security, safety, comfort etc. At the same time, during their everyday life the components have to support high current densities, because of the continuous shrinkage of new silicon technologies. The risk of failure is therefore physically increased, but has to be technically restrained to almost zero risk. In fact, power devices have to satisfy new robustness requirements to withstand the stress of repeated electro-thermal cycles for all the vehicle's life. In this context, the comprehension of the failure mechanisms under electro-thermal stress is a key point in the reliability assessment.

Because accidental failures due to intrinsic defects are now almost eliminated at the fabrication step, the most critical parts of power components are the metallic ones [1-4]. These parts are the source metallization (generally made out of aluminum) on top of the silicon wafer, and in particular the metallization beneath the bond wires, because it is the location of the highest concentration of current and temperature and because these parts age systematically. During the on-off operating cycles, the temperature changes result in mechanical stress due to the difference in the coefficients of thermal expansion (CTE) between the aluminum (Al) and the silicon (Si). Since aluminum has a low mechanical yield stress, the source metallization is expected to deform plastically even at moderate temperature excursions $\left(200{ }^{\circ} \mathrm{C}\right)$, whereas silicon remains in its elastic domain. The result is the wellknown phenomenon of Al surface reconstruction, which leads to an increase in the drain-source resistance $\left(\mathrm{R}_{\mathrm{dson}}\right)$ over cycles, until failure [5-8]. Whereas this reconstruction can lead to catastrophic failure has still to be determined.

In a previous study [9], we have shown that power MOSFETs aging occurs through a change in the Al grain microstructure and that plastic deformation of the top metal is due to an enhanced self-diffusion of the Al atoms along the grain boundaries [10,11]. We have also compared the initial Al metallization microstructure away from the bonding area and just under the bond wires: the latter is severely deformed, due to the bonding process. Moreover the wire-metallization interface shows initial imperfections, which probably are the starting point of crack propagation during aging.

This proves that the welded zone between the wire and the metallization is already deformed by the bonding process before aging. The thermomechanical stress, induced by the temperature cycles, weakens this interface and can lead to catastrophic events, such as bond wire lift off. Several studies focus on the bond wire failure mechanisms [2,4,12-14]. Bond wire heel crack failures [15] observed by experiments are found to be strongly dependent on the geometry and the thermal management of power devices. However, the fine characterization of the whole wiremetallization microstructure, which can provide useful feedback about the welding process, is poorly stated.

In the present study, we focus on the whole wire-metallization of power MOSFETs during accelerated aging tests. We characterize the microstructural evolution of the metallization just under the bonding wires, following a physical metallurgy approach: through scanning electron microscopy (SEM), focused ion beam (FIB) milling and microscopy, FIB-tomography, transmission electron microscopy (TEM) and grain structure mapping. These techniques are generally used to investigate the surface reconstruction phenomena of the naked metallization. In this study, thanks to a dedicated sample preparation that allows us to preserve the integrity of the bond interface, we could exploit them to follow the fine effects of the electro-thermal aging at this critical location.

\section{Experimental procedure}

\subsection{Device under test and accelerated aging tests}

The device under test (DUT) is a $12 \mathrm{~V} \mathrm{SmartMOS}^{\circledR}$ module from NXP Semiconductors designed for car applications. The device includes a power die, the active zone, and a control die, with diagnosis and protection functionalities (Fig. 1a). The power die consists in five MOS sectors, connected by eight wedge bond wires made out of Al. Here, we focus on the Al source metallization (3.6 $\mu \mathrm{m}$ thick), together with the Al bonding wires $(381 \mu \mathrm{m}$ of diameter) attached to it. The $\mathrm{Al}$ metallization contains $0.5 \mathrm{wt} \%$ of copper $(\mathrm{Cu})$ and tungsten $(\mathrm{W})$ and is coated by 
a silicon oxide $\left(\mathrm{SiO}_{2}\right)$ passivation layer $(0.5 \mu \mathrm{m}$ thick $)$ everywhere, except in the bonding area to allow the electrical contact (Fig. 2a).

We performed specific aging tests (according to the AECQ100-12 standard [16]) at $25{ }^{\circ} \mathrm{C}$ and $70{ }^{\circ} \mathrm{C}$, putting the component under repetitive short-circuit conditions until it failed. The supply resistance and inductance are fixed at $\mathrm{R}=10 \mathrm{~m} \Omega$ and $\mathrm{L}=5 \mu \mathrm{H}$, which correspond to an output of Rshort $=50 \mathrm{~m} \Omega$ and Lshort $=5 \mu \mathrm{H}$. During the shortcircuit, the device detects an overload and shuts down (fig 1b). Energy is dissipated at this stage, leading to an increase in the device temperature up to $250{ }^{\circ} \mathrm{C}-300{ }^{\circ} \mathrm{C}$ and affecting the device aging conditions.

The operating lifetime is considerably lower for the components tested at higher temperatures (5.3million cycles at $25^{\circ} \mathrm{C}, 300 \mathrm{k}$ cycles at $70^{\circ} \mathrm{C}$ ). During the tests, only one sector undergoes repeated electrical pulses, so we could use the others as reference for the microstructural characterization of the metallic parts.
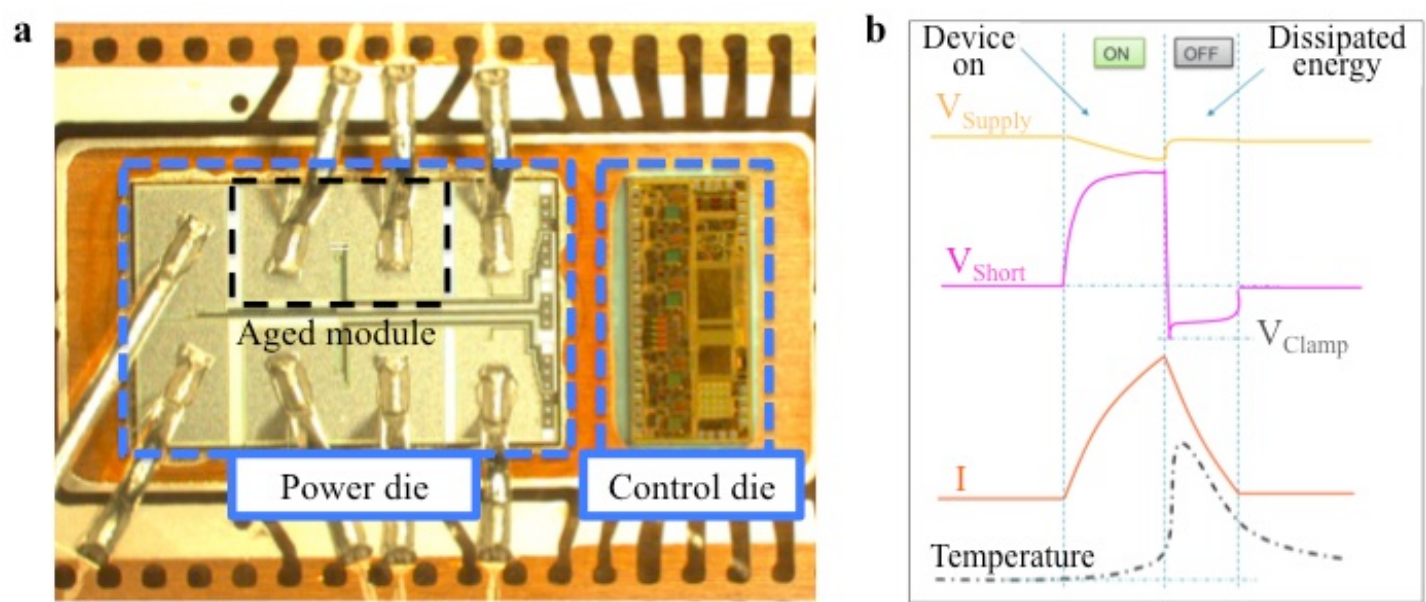

Fig. 1. (a) 12 V NXP's SmartMOS ${ }^{\circledR}$ including the power and the control die. (b) Typical signals during a short cycle event in the power MOSFET by activation of overload protection.

a

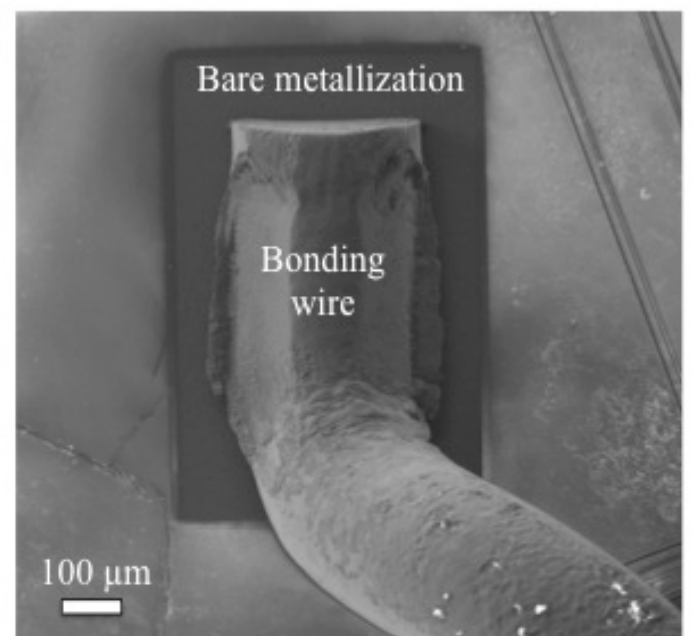

b

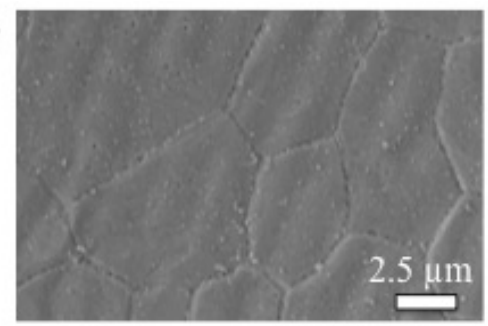

c

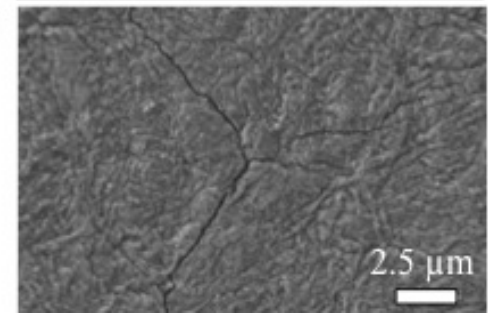

Fig. 2. (a) SEM image of an $\mathrm{Al}$ bond wire welded on the $\mathrm{Al}$ source metallization. Away from the bonding area the metallization is coated by a $\mathrm{SiO}_{2}$ passivation layer. At higher magnification, bare metallization (close to the bond wire) of an (b) as-is module and (c) an aged one. 


\subsection{Microstructural characterization}

Preliminary surface observations were performed in a Helios 600 FIB/SEM from FEI ${ }^{\mathrm{TM}}$. Fig. $2 \mathrm{~b}$ and $2 \mathrm{c}$ show the comparison between the Al metallization (close to the wire bonds, where the passivation layer is absent) before and after aging, confirming a heavy surface reconstruction upon aging.

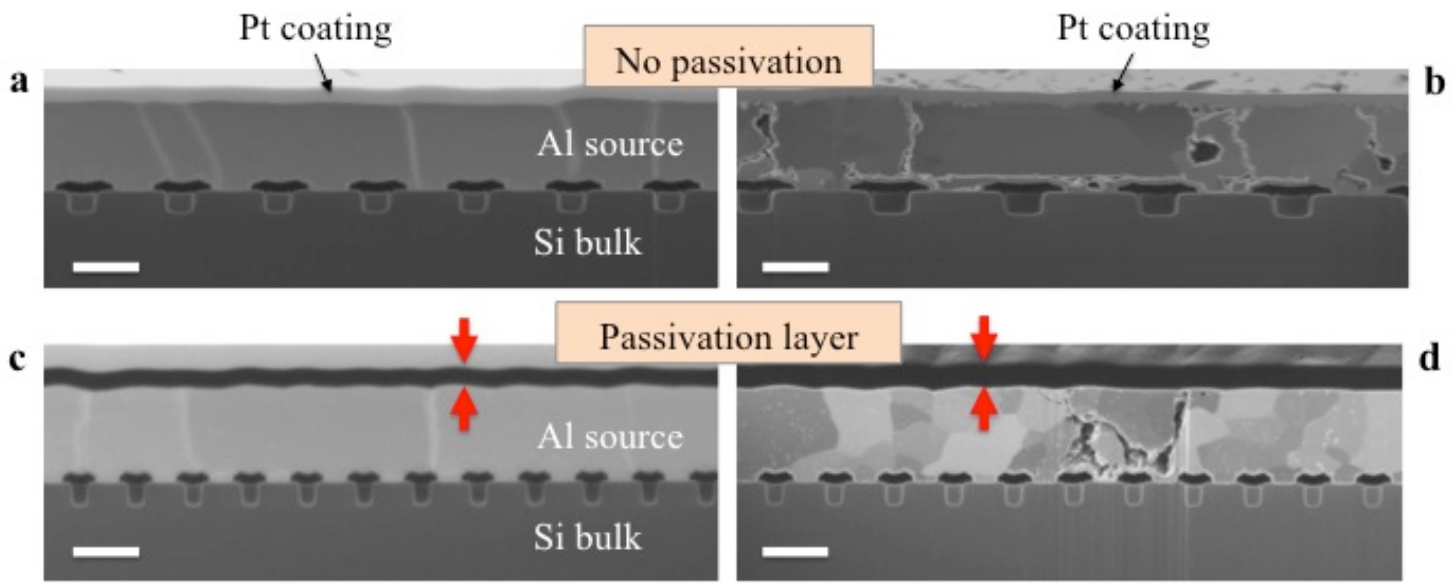

Fig. 3. FIB imaging of the bare metallization of an (a) as-is and (b) aged $\left(70^{\circ} \mathrm{C}\right)$ power module and of a $\mathrm{SiO}_{2}$ coated metallization in an (c) as-is and $(\mathrm{d})$ aged $\left(70^{\circ} \mathrm{C}\right)$ power module. The red arrows highlight the $\mathrm{SiO}_{2}$ passivation layer. Scale bar $2.5 \mu \mathrm{m}$.

The in-depth structure of the metallization away from the bonding area was observed by making cross-sectional cuts in the FIB/SEM microscope. These cross-sections are observed using ion channeling contrast, which depends on the grain orientation [17]. Fig. 3 shows the comparison between a non-aged module and an aged one and reveals a strong degradation of the aged metallization, both bare and passivated, with many cavities and cracks running from the surface down to the transistor region.

However, cross-sectional observation of the Al power metallization under the bonding wire requires a preliminary sample preparation of the device: this is because it's unfeasible to cut through the entire wire thickness by ion beam. At the same time, a mechanical polishing could induce mechanical damage of the wire-metallization interface while it is the object of the investigation, and also cause the wire lift off that is usually poorly attached in the case of an aged device,. This preparation (Fig. 4) combines a mechanical grinding of the bonding wires at $45^{\circ}$, in order to locally reduce the wires thickness, and a final ion polishing by FIB. The cross-section ion images at the wire-metallization interface (Fig. 5) give us a first idea about the quality of the bonding process. It also allows to measure the initial deformation imposed to the Al layer by the wire bonding process and investigate the behavior of this interface during aging.
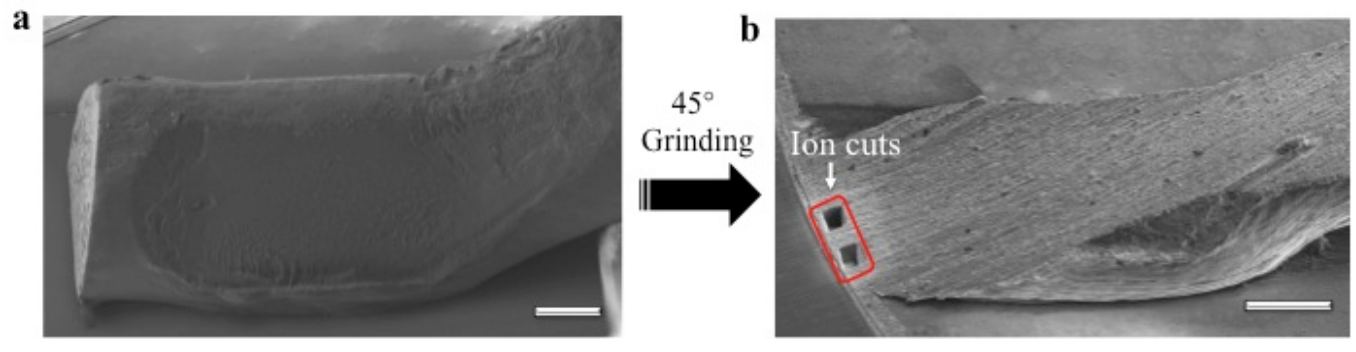

Fig. 4. (a) Bonding wire welded on the source metal of a power module. (b) The wire is cut and polished at $45^{\circ}$ before being cut by FIB for interface observation. Scale bar $100 \mu \mathrm{m}$. 


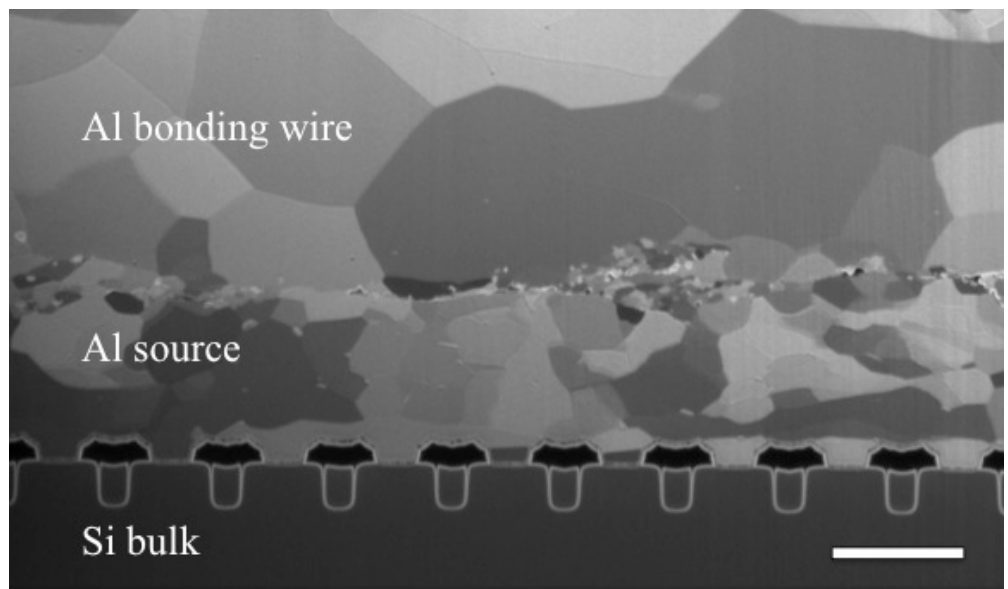

Fig. 5. FIB imaging of the wire-source metallization interface in an as-is power module. Scale bar $2.5 \mu \mathrm{m}$.

High-resolution 3D images are acquired in a Helios $600 \mathrm{FIB} / \mathrm{SEM}$, equipped with the Auto Slice and View software from $\mathrm{FEI}^{\mathrm{TM}}$. The FIB-tomography consists in the following steps: 1) preparation of a parallelepiped of user-defined size, 2) creation of a reference mark, close to the area of interest, for the automated drift correction, 3) serial sectioning and acquisition of a SEM images stack. The sample is placed at the eucentric position, where the ion and the electron beam converge with an angle of $52^{\circ}$ (Fig. 6). While the ion beam is used to cut and polish serial thin slices, the relative images are acquired by the electron column. The result is a stack of electron images at the wire-metal interface, which allows to follow the crack propagation inside an aged module volume. In our experiments we collected a stack of 200 SEM images with a z-spacing of $50 \mathrm{~nm}$.

Finally, thin lamella (Fig. 7a, 7b) are FIB-prepared for the in-depth investigation of the source metallization and the wire-metal interface by TEM. Electron energy loss spectroscopy (EELS) are carried out in a Tecnai ${ }^{\mathrm{TM}}$ F20 microscope, in order to investigate the chemical composition of the wire-metal interface. TEM observations are also performed in a CM20FEG equipped with a Digistar ${ }^{\mathrm{TM}}$-ACOM unit from NanoMEGAS ${ }^{\mathrm{TM}}$. This system acquires the diffraction patterns of a TEM sample and returns the crystallographic orientation of each scanned point to build orientation maps as in Fig. 7c.
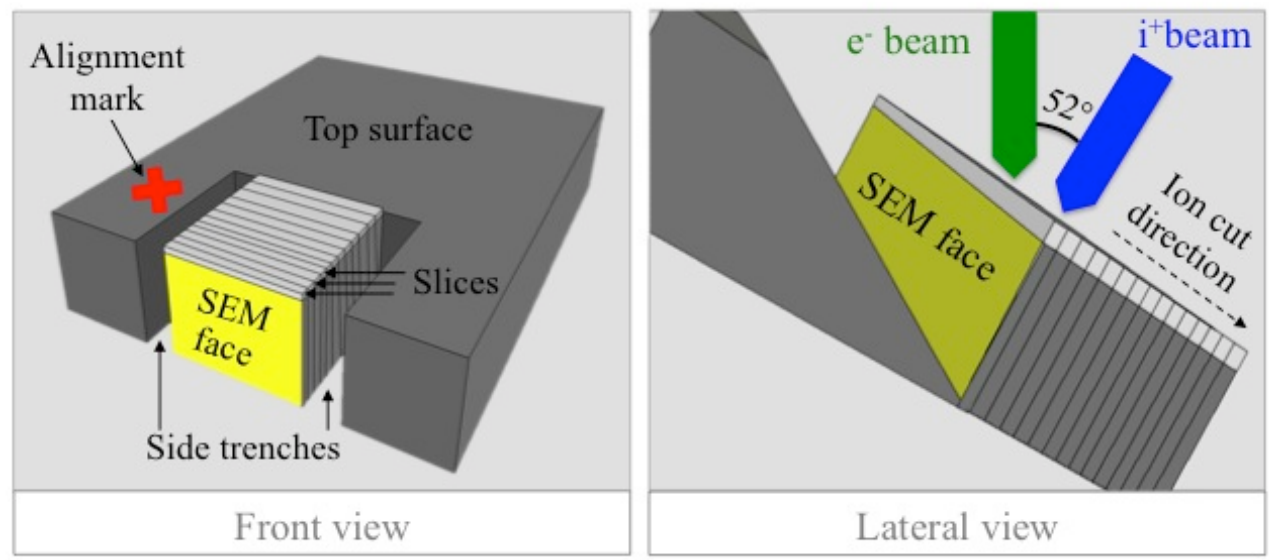

Fig. 6. Schematic illustration of the serial sectioning procedure by dual-beam FIB. 

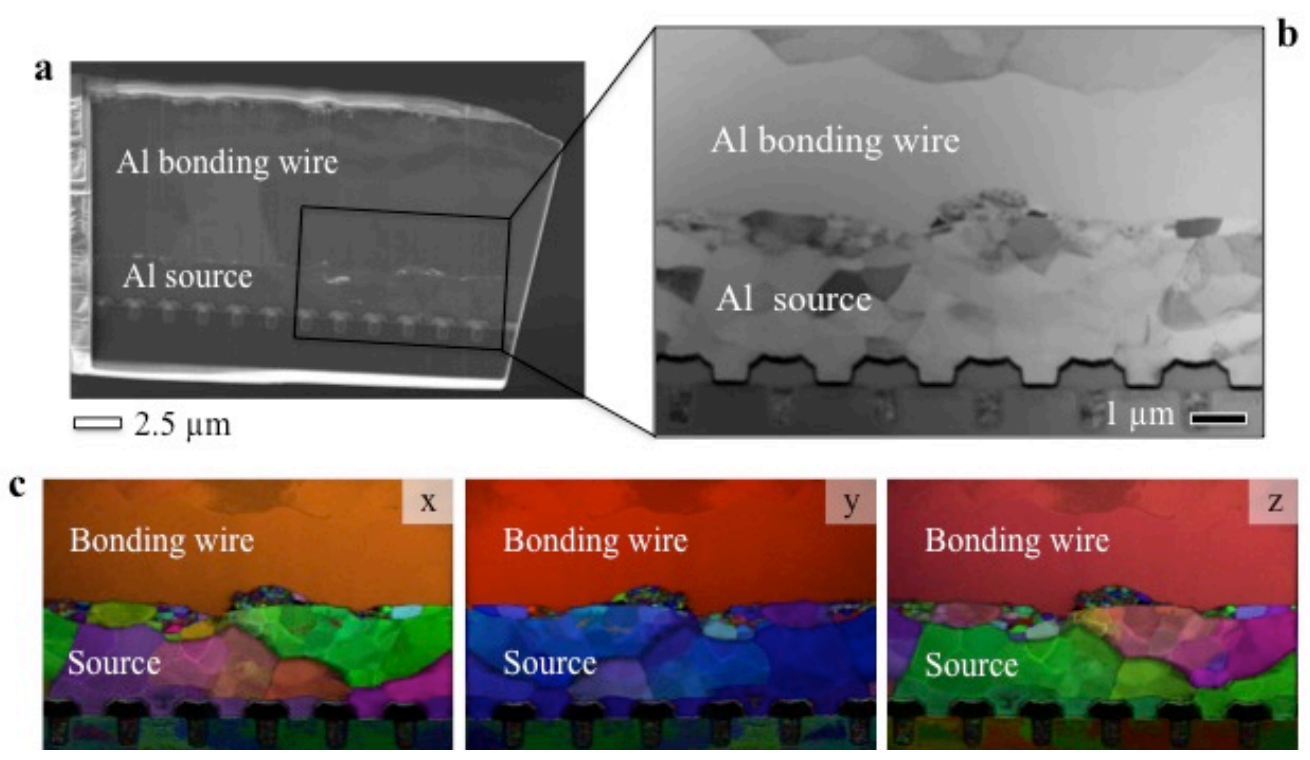

Fig. 7. (a) SEM image of a FIB-prepared lamella from an as-is module and (b) TEM detail of the wire-metal interface, with (c) the relative ACOM orientation maps.

\section{Results and discussion}

\subsection{Al metallization away from the bonding area}

Outside of the bonding area, the initial Al metallization is characterized by a "bamboo" grain structure (Fig. 3a, $3 c)$ : the grain size is on the same order of the metallization thickness and most of the grain boundaries run perpendicular to the surface down to the Si substrate.

FIB images of aged modules (Fig. 3b, 3d) show that the repetitive electro-thermal cycles cause the formation of cavities and cracks running from the surface to the transistor region. They follow the grain boundaries, confirming that aging is linked to an enhanced self-diffusion of $\mathrm{Al}$ atoms along the boundaries [10,11]. Moreover aging seems to lower the average grain size but, as we also observed in a previous work [9], ACOM mapping (Fig. 8) shows that most of the grain domains revealed by FIB have a small misorientation (less than $10^{\circ}$ ). This means that they are subgrains formed by the eraly gathering of pre-existing dislocation inside a single initially large bamboo grain, and the apparent size reduction is only a FIB artifact.

Under the passivation, the Al diffusion process along the grain boundaries is supposed to be cut off or at least slowed down $[10,18]$. Fig. $3 \mathrm{~d}$ shows that plastic deformation in the passivated Al metallization is less homogeneous than in the passivation-free metallization: some zones are not aged, whereas in others we observe a weak concentration of cracks and cavities.
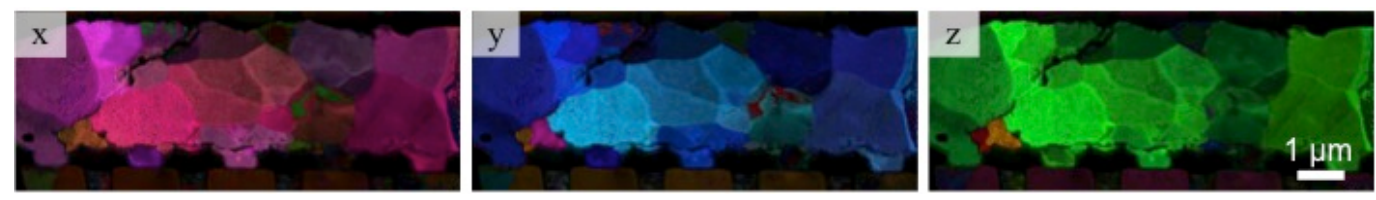

Fig. 8. ACOM maps of the naked metallization of an aged module $\left(70^{\circ} \mathrm{C}\right)$. 


\subsection{Al metallization under the bonding wires}

Under the bonding wire, the Al metallization has endured plastic deformation due to the welding process. Fig. 5 and $7 \mathrm{c}$ shows that the initial grain size is systematically smaller in these zones, compared to the bamboo structure (Fig. 3a, 3c) of the naked metallization. One can also notice that grains in the Al wire are much larger. Plastic deformation is highly uneven. Perpendicularly to the wire-metal interface (along the applied stress of the wire bonding), this deformation ranges from $2 \%$ to $27 \%$ in average in the measured sections. To obtain these values, we have used the measurement method illustrated in Fig. 9. We measure the deformation with respect to a reference (red line) by computing the metallization areas under (zone -) or over (zone + ) the reference, which corresponds to the initial position of the metallization surface. Then the deformation is computed as:

$$
\text { DeformedAreaRatio }=\frac{\text { Area }_{D E F}}{\text { Area }_{\text {REF }}}
$$

where:

$$
\begin{aligned}
& \operatorname{Area}_{D E F}=\sum_{i} A_{i} \\
& \text { Area }_{R E F}=l_{c u t} * h_{r e f}
\end{aligned}
$$

This measurement method takes in account the fact that the initial deformation is not uniform along the wiremetallization interface, that the interface is not straight, and that extrusion or compression of the metallization occurs during the bonding process. We can clearly see it in Fig. 10, showing two closed cross-sections of the Al metallization under the same bonding wire: in the first one (Fig. 10a) the wire-metal interface is almost straight without deformation, whereas in the second one (Fig. 10b) a severe plastic deformation significantly changes the interface profile, provoking a thinning of the metallization on the sides of the micrograph and a bulging in the middle. In the measured areas, the maximum deformation peaks to about $36 \%$, both in depression or extrusion. Average deformation is about $10 \%$, no matter the direction of deformation.

The surface impacted by the wire is about $0.25 \mathrm{~mm}^{2}$, which, taking in account the pressure applied during the ultrasonic process, leads to an average compressive stress of $35 \mathrm{MPa}$. This stress is much smaller than the yield stress of a commercially pure Al with a grain size in the range of $1-2 \mu \mathrm{m}$, typically in the range of $100-150 \mathrm{MPa}$ [19]. To explain that significant plastic deformation occurred under this small load, we have to assume that only a fraction of the $0.25 \mathrm{~mm}^{2}$ of the metallization surface was truly in contact with the wire. A very coarse estimate would lead to a third of the metallization being impacted by wire-bonding plastic deformation. This also explains why the surface is deformed very inhomogeneously.

Upon aging, we locally measured the deformation by taking the initial metallization thickness away from the bonding wire (in a non-aged device) as reference. The amount of plastic deformation does not change significantly, in line with previous results [9]. 


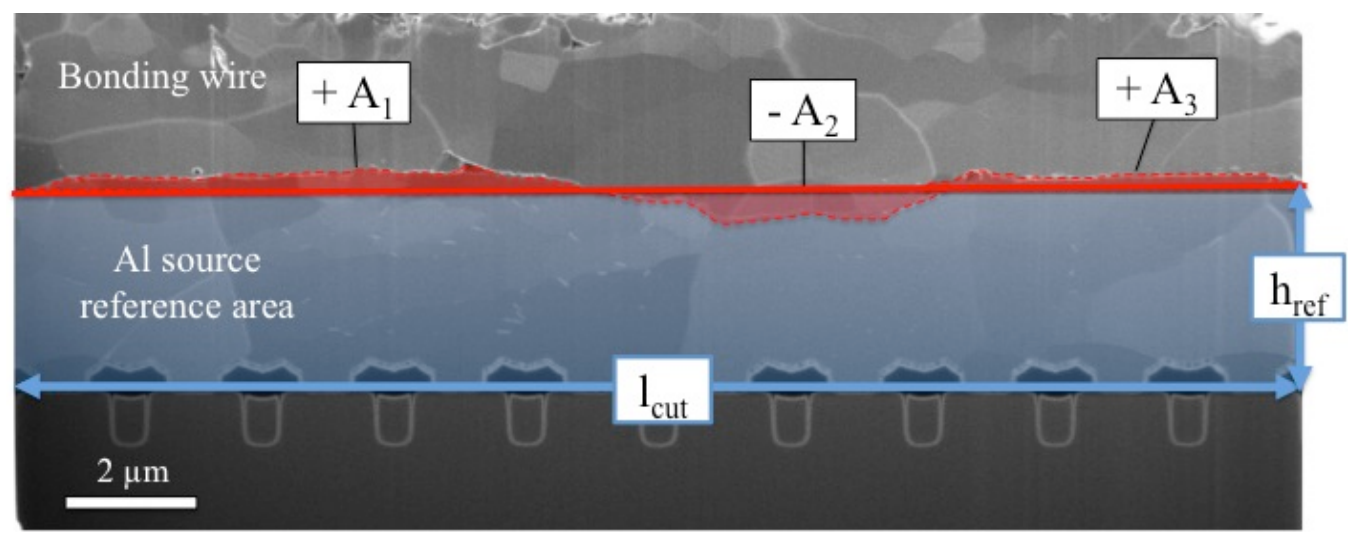

Fig. 9. Schematic illustration of the measurement of the plastic deformation imposed to the Al source metallization by the bonding process.
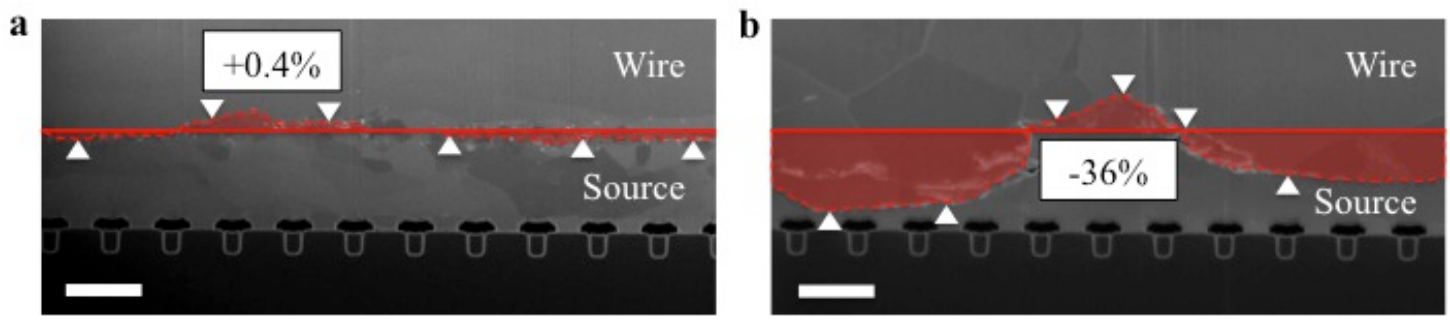

Fig. 10. FIB images of the wire-metallization interface in two closed areas under the same bonding wire. The images refer to a non-aged module. Scale bar $2.5 \mu \mathrm{m}$.
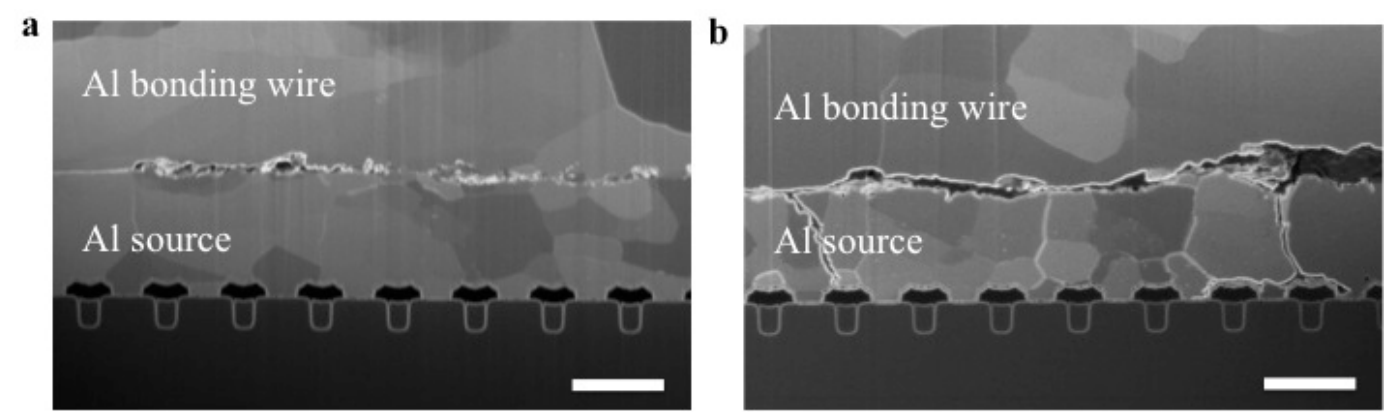

Fig. 11. FIB images of the wire-metallization interface in (a) an as-processed module and in (b) an aged one (at $25^{\circ} \mathrm{C}$ ). Scale bar $2.5 \mu \mathrm{m}$. 


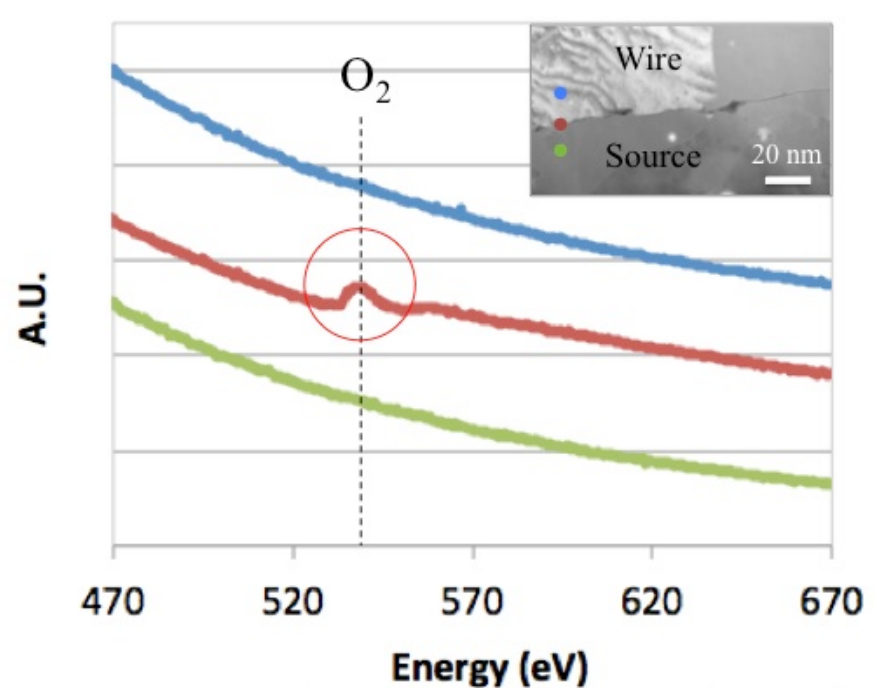

Fig. 12. EELS spectra from the wire (in blue), the metallization (in green) and the wire-metallization interface (in red). The red spectrum at the wire-metallization interface reveals the presence of oxygen.

\subsection{Wire-metallization interface}

The bonding between the metallization and the wire is characterized by initial imperfections, visible in white contrast in fig. 10 and 11a. Fig. 12 shows the EELS spectra from the wire (in blue), the metallization (in green) and the wire-metallization interface (in red). The spectrum at the wire-metallization interface reveals the presence of oxygen, proving that the initial imperfections are linked to the presence of Al oxide. The most probable explanation for this presence is that this native oxide is not fully broken during the bonding process.

During aging, cracks propagate along these imperfections (Fig. 11b), causing a reduced contact between the wire and the metallization or, at worst, the wire lift-off. Cracks also run perpendicularly to the interface under the wires, as in the metallization away from the bonding area.

Crack propagation upon aging is investigated by FIB-tomography experiments. In Fig. 13, a series of six (non consecutive) SEM images from the wire-metallization interface of a $70{ }^{\circ} \mathrm{C}$ aged module are showed. In the analyzed area, the contact between the wire and the metallization is severely affected by the electro-thermal aging (image $n^{\circ}$ 1). A measure of the horizontal delamination surface using the complete stack of tomographic SEM sections leads to a delamination ratio of $78 \%$ over the tested volume. If we assume that about $33 \%$ of the wire was attached to the metallization (see paragraph 3.2), then delamination affected another $10 \%$ of the expected contact during aging. Of course, the volume tested by FIB is too small to make robust statistics, but we have gathered convergent observations showing that a significant delamination occurs between the wire and the metallization it's attached to. Going through the metallization volume, one can note some cavities appear (image $\mathrm{n}^{\circ} 43$ ) and subsequently constitute a single crack running from the bond interface to the transistor area (image $\mathrm{n}^{\circ} 118$ ). This crack splits in two new cracks (images $n^{\circ} 135$ and 166) that propagate in the Al metallization (image $n^{\circ} 176$ ). The high density of metal breaks revealed by the tomography stack can explain the increase of the $\mathrm{R}_{\mathrm{dson}}$, which implies that subsequent electrical pulses will generate more heat, thus more deformation, and crack propagation.

The same aging mechanisms are observed in devices tested at $25{ }^{\circ} \mathrm{C}$ and $70{ }^{\circ} \mathrm{C}$. Fig. 14 shows the comparison between two cross-section images of a $25^{\circ} \mathrm{C}$ and $70^{\circ} \mathrm{C}$ aged metallization under the bonding contact. In both cases, cracks propagate horizontally along the wire-metallization interface and perpendicularly to the surface down to the transistor region. However a higher test temperature can accelerate this behavior, explaining the lower life-time of the components aged at $70{ }^{\circ} \mathrm{C}$. In these tests, the self passivation of the Al layers are observed as the thickness of the 
initial oxide keeps increasing upon aging, which is in agreement with the observation of oxygen content increase in the metallization of diodes undergoing electro-thermal aging [20]. However, contrary to what has been observed by these authors, this growth does not prevent the propagation of cracks.
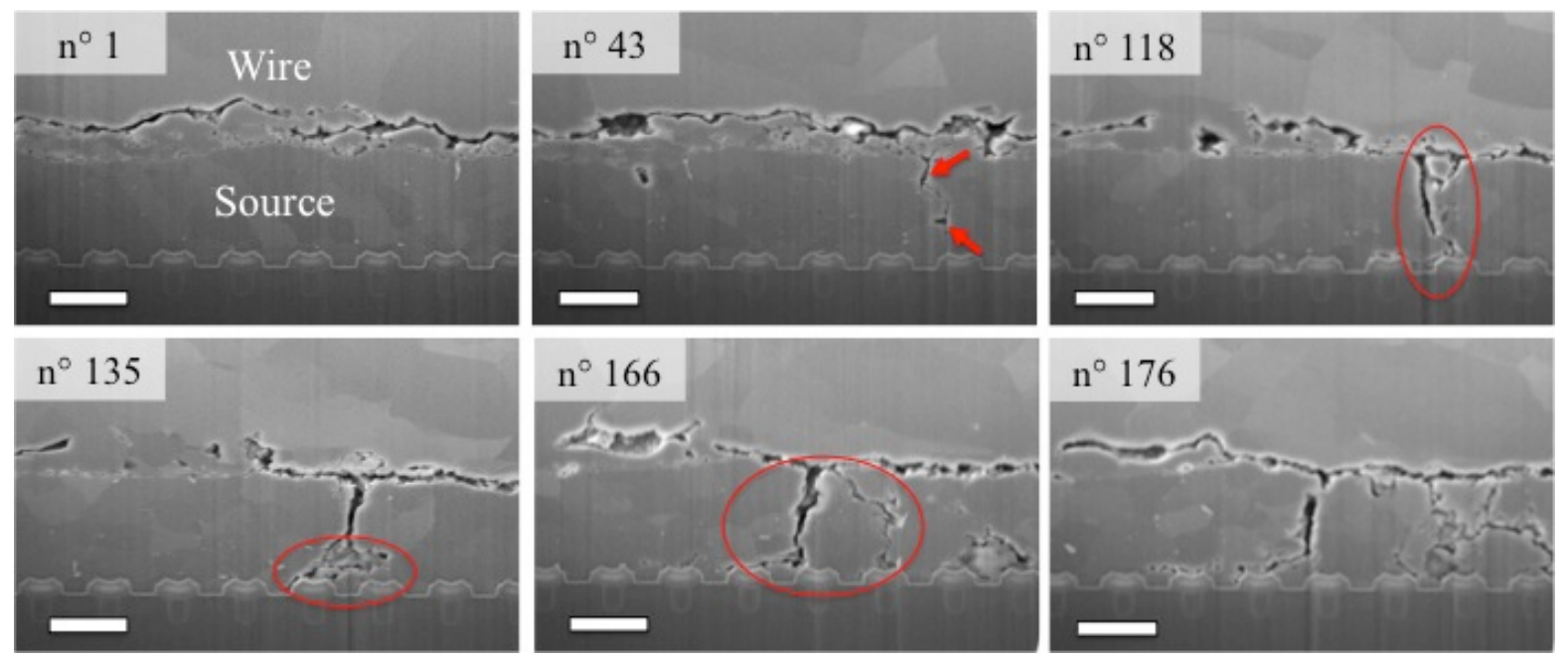

Fig. 13. Selection of six non consecutive SEM images from the data stack of the wire-metallization interface of a $70{ }^{\circ} \mathrm{C}$ aged device (slicing distance $50 \mathrm{~nm}$ ). Scale bar $2.5 \mu \mathrm{m}$.
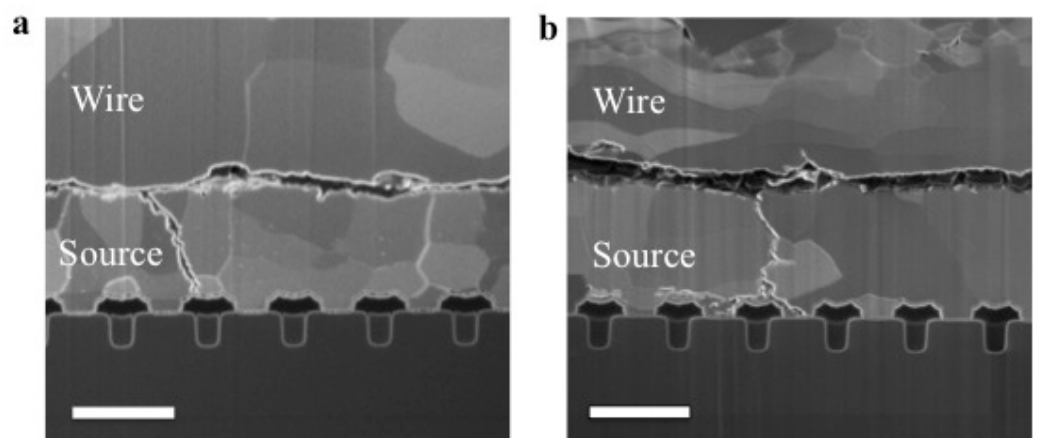

Fig. 14. FIB images of the wire-metallization interface of a device aged at $25^{\circ} \mathrm{C}$ and $70{ }^{\circ} \mathrm{C}$. Scale bar $2.5 \mu \mathrm{m}$.

\section{Conclusions}

The electro-thermal aging of the Al-based source metallization of power MOSFETs has been assessed by systematic observations of its microstructure.

Away from the wire bonds, the metallization is characterized by an initial "bamboo" structure (with the grain size of the same order of the metallization thickness). During aging, it undergoes a limited plastic deformation (apparent grain shrinkage, due to FIB artifacts) but several cracks are observed to run perpendicular to the surface down to the Si substrate, following the grain boundaries.

Under the wire bonds, the initial microstructure is finer than elsewhere because of the plastic deformation imposed by the bonding process. Upon aging a strong grain growth is observed. Moreover, cracks propagate not only perpendicularly to the surface, but also horizontally, along the wire-metallization interface. These cracks 
originate from the residual aluminum oxide, not fully broken during the bonding process. Because of this extensive horizontal crack propagation in aged devices, the remaining contact area between the wire and the metallization is reduced to a portion of the expected contact area, which appears as a probable source of device failure.

The aging of the Al metallization, both away and under the wire bonds, can be associated to a heavy generation of cracks that, cycle after cycle, are bound to propagate inside the material because of the auto-passivation of the Al around them. Two main mechanisms have been identified behind this behavior: 1) an enhanced self-diffusion of the $\mathrm{Al}$ atoms along the grain boundaries and 2) a poor bonding of the wires. In both cases, the result is an increase in the $\mathrm{R}_{\mathrm{dson}}$ of the devices during electro-thermal aging, leading to failure.

\section{References}

[1] A. Irace, G. Breglio, P. Spirito, R. Letor, S. Russo, Microelectron. Reliab. 45 (2005) 1706-1710.

[2] M. Glavanovics, T. Detzel, K. Weber, Proc. 30th Eur. Solid-State Circuits Conf. (2004) 273-276.

[3] S. Pietranico, S. Lefebvre, S. Pommier, M. Berkani Bouaroudj, S. Bontemps, Microelectron. Reliab. 51 (2011) $1824-1829$.

[4] M. Ciappa, Microelectron. Reliab. 42 (2002) 653-667.

[5] B. Khong, P. Tounsi, P. Dupuy, X. Chauffleur, M. Legros, A. Deram, C. Levade, G. Vanderschaeve, J.M. Dorkel, J.P. Fradin, Microelectron. Reliab. 45 (2005) 1717-1722.

[6] B. Bernoux, R. Escoffier, P. Jalbaud, J.M. Dorkel, Microelectron. Reliab. 49 (2009) 1341-1345.

[7] G. Rostaing, M. Berkani Bouaroudj, D. Mechouche, D. Labrousse, S. Lefebvre, Z. Khatir, P. Dupuy, Microelectron. Reliab. 53 (2013) 1703-1706.

[8] D. Martineau, T. Mazeaud, M. Legros, P. Dupuy, C. Levade, Microelectron. Reliab. 50 (2010) 1768-1772.

[9] R. Ruffilli, M. Berkani Bouaroudj, P. Dupuy, S. Lefebvre, Y. Weber, M. Legros, Microelectron. Reliab. 55 (2015) $1966-1970$.

[10] H. Gao, L. Zhang, W.D. Nix, C. V. Thompson, E. Arzt, Acta Mater. 47 (1999) 2865-2878.

[11] D. Martineau, C. Levade, M. Legros, P. Dupuy, T. Mazeaud, Microelectron. Reliab. 54 (2014) 2432-2439.

[12] S. Ramminger, N. Seliger, G. Wachutka, Microelectron. Reliab. 40 (2000) 1521-1525.

[13] H. Köck, C. Djelassi, S. De Filippis, R. Illing, M. Nelhiebel, M. Ladurner, M. Glavanovics, D. Pogany, Microelectron. Reliab. 51 (2011) 1913-1918.

[14] P. Dietrich, Microelectron. Reliab. 54 (2014) 1901-1905.

[15] V. Mehrotra, J. He, M.S. Dadkhah, K. Rugg, M.C. Shaw, Proc. ISPSD. (1999) 113-116.

[16] M.A. Kelly, E. Al, Automotive Electronics Council (2006).

[17] T. Ishitani, H. Tsuboi, Scanning. 19 (1997) 489-497.

[18] O. Kraft, L.B. Freund, R. Phillips, E. Arzt, Dislocation plasticity in thin metal films, MRS Bull. 27 (2002) $30-37$.

[19] N. Tsuji, Y. Ito, Y. Saito, Y. Minamino, Scr. Mater. 47 (2002) 893-899.

[20] M. Brincker, K.B. Pedersen, P.K. Kristensen, V. Popok, Conf. Pap. (2016). 